\title{
New developments in the management of hepatitis $C$ virus infection: focus on boceprevir
}

This article was published in the following Dove Press journal:

Biologics:Targets and Therapy

2 August 2012

Number of times this article has been viewed

\author{
Marina Berenguer ${ }^{1-3}$ \\ F Xavier López-Labrador ${ }^{4-6}$ \\ 'Hepatology-Liver Transplantation \\ Unit, Digestive Medicine Service, \\ Hospital Universitari La Fe, Valencia, \\ Spain; ${ }^{2}$ Department of Medicine, \\ University of Valencia, Valencia, \\ Spain; ${ }^{3} \mathrm{ClBER}$ ehd, Instituto de \\ Salud Carlos III, Madrid, Spain; \\ ${ }^{4}$ CSISP, Center for Public Health \\ Research, Public Health Department, \\ Generalitat Valenciana, Valencia, \\ Spain; ${ }^{5}$ Microbiology Department \\ and Institut Cavanilles, University of \\ Valencia, Valencia, Spain; ${ }^{6}$ CIBEResp, \\ Instituto de Salud Carlos III, Madrid, \\ Spain
}

\begin{abstract}
Chronic hepatitis $\mathrm{C}$ virus infection is an important public health problem, and the standard treatment (combination of pegylated interferon- $\alpha$ and ribavirin) has an effectiveness rate of only $40 \%-50 \%$. Novel virus-specific drugs have recently been designed, and multiple compounds are under development. The approval for the clinical use of direct-acting antivirals in 2011 (boceprevir [BOC] and telaprevir, viral NS3 protease inhibitors) has increased recovery rates by up to $70 \%$. Therefore, a highly effective treatment has been envisioned for the first time. This paper focuses on BOC and the implementation of new BOC-based treatment regimes.

Keywords: $\mathrm{HCV}$, antiviral therapy, protease inhibitors, viral resistance
\end{abstract}

\section{Epidemiology, management, and emerging treatments for hepatitis $C$ virus}

Chronic hepatitis $\mathrm{C}$ virus (HCV) infection is a global public health concern because the infection progresses to end-stage liver disease, hepatocellular carcinoma, and liver failure in a considerable number of infected individuals. Once end-stage liver disease is established, the only reliable therapeutic intervention is liver transplantation, but viral recurrence is inevitable and the graft can be lost in a few years. Until recently, the standard-of-care (SOC) for treatment was based on a combination of pegylated interferon- $\alpha$ (peg-IFN $\alpha$ ) and ribavirin (RBV), which is effective in $40 \%$ of patients infected with $\mathrm{HCV}$ genotype $1 .{ }^{1} \mathrm{New}$ therapies that improve current treatment response rates will be based in specific inhibitors of viral enzymes. Among them, two inhibitors of the viral NS3/4A serine-protease have recently been approved for clinical use. Telaprevir (TPV) (Vertex Pharmaceuticals, Cambridge, MA, USA) and boceprevir (BOC) (Merck and Co, Whitehouse Station, NJ, USA) - the first direct-acting antivirals (DAAs) for HCV to reach the clinical level - will have an impact in new treatment regimes for HCV. In some countries, a new SOC is now available for patients infected with HCV genotype 1, based on a combination of either TPV or BOC with peg-IFN- $\alpha$ and RBV. The introduction of these new regimes increases response rates by to up $75 \%$ in treatment-naïve patients infected with HCV genotype 1, and up to $50 \%$ in previous partial responders and relapsers who used the peg-IFN- $\alpha+$ RBV treatment. Variations in the latter group depend on the type of the previous response (see below). ${ }^{2}$ Neither BOC nor TPV are indicated to treat infection caused by other HCV genotypes.

\section{Current management approaches for HCV infection}

Peg-IFN- $\alpha$ and RBV are not DAAs, but rather, immunomodulators. Although RBV may act as an immunomodulator and increases $\mathrm{HCV}$ mutation rates, the mechanism 
for HCV inhibition is largely unknown. ${ }^{3,4}$ Almost all patients who achieve sustained virological response (SVR, absence of detectable HCV RNA in serum 24 weeks after the end of treatment) are considered to be cured from the infection, although negativity at 12 weeks is an increasingly used metric. ${ }^{5}$ Patients with SVR show histological and clinical improvements with regression of fibrosis, decreased risk for hepatocellular carcinoma, and overall reduction of liverrelated morbidity and mortality. ${ }^{6}$ Treatment success depends on the viral genotype, the stage of liver fibrosis, coexistence of a metabolic syndrome, age, sex, ethnicity, and host genetics. $^{7}$ The strongest predictor of treatment response is genetic polymorphism upstream from the interferon lambda-3 gene, IL28B. The most favorable genotypes are rs $12979860 \mathrm{C} / \mathrm{C}$, rs $12980275 \mathrm{~A} / \mathrm{A}$, and rs8099917 T/T; the three SNPs in linkage disequilibrium and more common in Asians and Caucasians. ${ }^{8}$ Regardless of the $I L 28 B$ genotype, SVR is approximately $40 \%$ in patients infected with HCV genotype 1 , and ranges from $60 \%-80 \%$ in those infected with genotypes 2 and 3. ${ }^{1}$ Side effects include flu-like symptoms, anemia, rash, cough, and depression. Serious adverse events (AEs) are uncommon, but may result in death. While dose reductions are frequently required, particularly doses of $\mathrm{RBV}$, treatment discontinuation due to AEs is rarely required (approximately 5\%). Unfortunately, dose reductions greater than $20 \%$ - especially for RBV - and premature treatment discontinuation reduce the chance of achieving SVR. ${ }^{7}$

\section{New developments in HCV treatment}

The first DAAs for the treatment of HCV chronic infection were approved in 2011 by the Food and Drug Administration and the European Medicines Agency for use in the United States and European Union, respectively. BOC and TPV are each given in combination with Peg-IFN- $\alpha$ and RBV for the treatment of genotype 1 chronic hepatitis $C$ in adult patients with compensated liver disease. ${ }^{9,10}$ Both drugs are specific inhibitors of the HCV NS3/4A protease. These protease inhibitors (PI) interfere with the virus' life cycle and inhibit the processing of the viral polyprotein, and likely restore the pathways of the innate immunity. ${ }^{11}$ Several second-generation HCV NS3/4A protease inhibitors are currently being developed, such as ITMN-191, TMC435350, and MK-7009. ${ }^{12}$ DAAs that target other HCV proteins are also being evaluated, such as NS4A, NS4B, NS5A, and NS5B polymerase inhibitors; some with highly promising results. ${ }^{12}$

\section{Mode of action, safety, and efficacy of BOC}

BOC (SCH503034) is a carboxamide-based HCV NS3/4A oral protease inhibitor (Figure 1), which is an $\alpha$-ketoamide that forms a stable, covalent and reversible complex with the viral enzyme that inhibits the cleavage of the non-structural part of the HCV polyprotein. BOC reacts with the $\operatorname{Ser}^{139}$ of the active site (serine trap inhibitor), thus compromising the catalytic triad, $\mathrm{His}^{57}-\mathrm{Asp}^{81}-\mathrm{Ser}^{139}$. In cell culture, BOC suppresses $\mathrm{HCV}$ replicon synthesis with $\mathrm{IC}_{50}$ and $\mathrm{IC}_{90}$ values of $200 \mathrm{nM}$ and $400 \mathrm{nM}$, respectively. ${ }^{13}$ The antiviral activity was unaffected by the addition of IFN- $\alpha .{ }^{13}$ BOC has shown a beneficial and safe profile for the treatment of chronic HCV genotype 1 infections in combination with Peg-IFN- $\alpha$ and RBV in adult patients with compensated liver disease, including compensated cirrhosis. ${ }^{14,15}$ Currently, neither BOC nor TPV should be used in patients infected with HCV
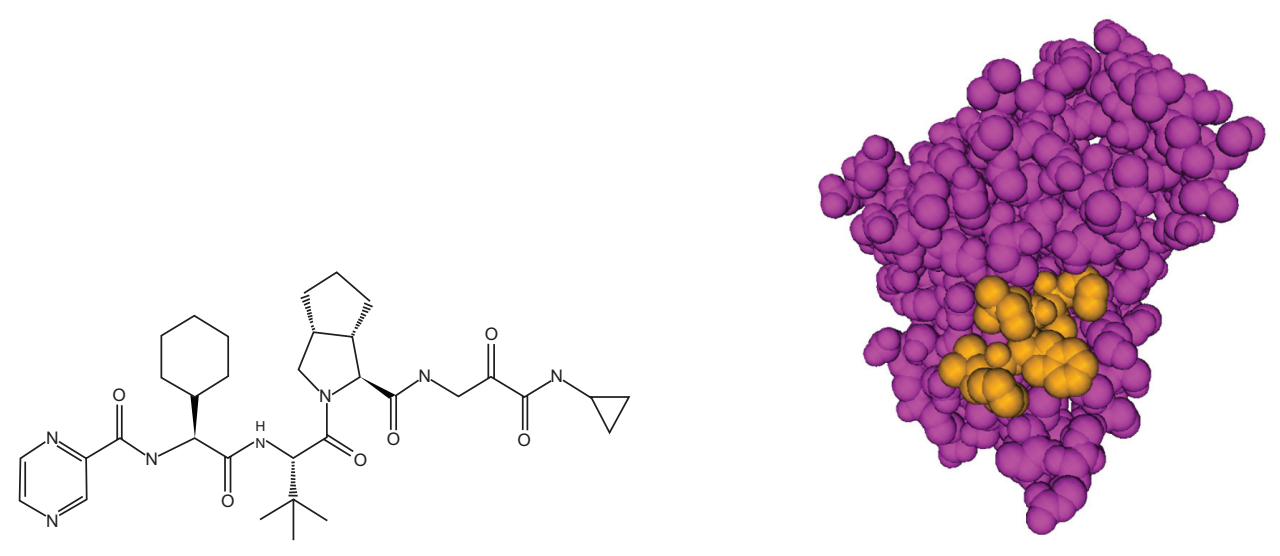

Figure I BOC, a ketoamide inhibitor of the HCV NS3 protease.

Notes: The molecular model shows one molecule of one BOC derivate (yellow) docked on the NS3 protease substrate (pink). The model was constructed using the structure deposited in public databases with PDB ID 3KN2.58,59 
genotypes other than genotype 1. Data on the efficacy of firstgeneration protease inhibitors in non-genotype 1-infected patients is scarce, which indicates some activity in HCV genotypes 2 and 4, but very limited activity in genotype 3 -infected patients. ${ }^{16}$ The clinical efficacy of BOC in adult individuals with chronic HCV genotype 1 infections was established in Phase II and Phase III studies examining the use of BOC both in SOC treatment-naïve and in SOC treatmentexperienced subjects (relapsers and non-responders).

The Phase II study, P03659 (NCT00160251), evaluated the use of BOC (100-800 mg three times daily + SOC) in 357 genotype 1-infected patients from the United States and Europe who were previous non-responders to SOC. The study established that $800 \mathrm{mg}$ was the optimal dose of BOC and that RBV was required to reduce viral breakthrough. ${ }^{17}$ The Phase II study, SPRINT-1, evaluated the SVR rates of triple therapy (BOC $800 \mathrm{mg}$ three times daily + peg-IFN$\alpha 2 b+R B V$ for 24 or 48 weeks) in 520 treatment-naïve patients infected with HCV genotype 1, compared to the standard Peg-IFN- $\alpha 2 b+$ RBV therapy, as well as reducing the RBV dose $(n=75) \cdot{ }^{18,19}$ The triple combination arm, with a treatment duration of 48 weeks, showed a significantly higher SVR rate $(67 \%)$ than the SOC control arm (38\%) and the reduced RBV arm (36\%). The rates of SVR were even higher (75\%) when a 4-week lead-in of SOC was administered before initiating BOC + peg-IFN- $\alpha 2 b+\mathrm{RBV}^{18,20}$ The lead-in phase aimed to limit the emergence of the BOC-resistant virus by reducing viral replication before the start of BOC. This study indicates that adding a single DAA to current HCV treatment significantly increased the SVR rates, but that pegIFN- $\alpha+$ RBV were still necessary for achieving SVR when using only one DAA. In addition, using a lead-in phase of SOC before BOC was initiated appeared to modestly reduce the chance of viral breakthrough, and ultimately, the chance of resistance (9/206 versus 19/210) viral breakthroughs in patients with or without lead-in, respectively. ${ }^{20}$

Two Phase III trials (SPRINT-2 and RESPOND-2) evaluated 48-week treatment strategies with responseguided therapy in patients with no detectable HCV-RNA at week 8 who later stopped treatment at week 28 (SPRINT-2) or week 36 (RESPOND-2). The SPRINT-2 trial was performed in 1097 treatment-naïve patients who were infected with HCV genotype 1 by dividing them in two cohorts of nonblack $(n=938)$ and black $(n=159)$ patients. Both cohorts were randomized into three arms: (1) peg-IFN $\alpha-2 b+R B V$ for 48 weeks, (2) BOC + peg-IFN $\alpha-2 b+$ RBV responseguided, and (3) BOC + peg-IFN $\alpha-2 b+R B V$ for 44 weeks.
All three arms included a peg-IFN $\alpha-2 b+$ RBV lead-in phase during the first 4 weeks. For white patients, the SVR rates were $67 \%$ and $68 \%$ in the response-guided arm and the 48 -week arm, respectively, compared to $40 \%$ with SOC for 48 weeks. ${ }^{15,21}$ For black patients, the SVR rates were $42 \%$ and $53 \%$ in the response-guided and 48 -week arms, respectively, compared to $23 \%$ with SOC for 48 weeks. ${ }^{15,21}$ Overall, the SVR rates between the response-guided and fixed duration BOC arms were not significantly different in the SOC-naïve patients, and the lead-in phase was not associated with increased efficacy. The rates of SVR in both BOC arms were significantly higher, compared to the controls (peg-IFN $\alpha-2 b+$ RBV alone) in the previously untreated adult cohort with chronic HCV genotype 1 infection.

The RESPOND- 2 trial was performed on 403 treatmentexperienced patients who failed SOC therapy (excluding null responders) and evaluated the two treatment strategies mentioned above. The final results indicate that overall SVR rates were $59 \%$ and $66 \%$ in the response-guided and 48 -week arms, respectively, compared to $21 \%$ for the retreatment with SOC alone for 48 -weeks. ${ }^{14,19}$ Therefore, the rates of SVR were not significantly different from the response-guided and fixed duration therapy with BOC + peg-IFN $\alpha-2 b+R B V$ for 44 weeks for SOC-experienced patients. However, the SVR rates in both BOC arms were significantly higher than the controls group (retreatment with peg-IFN $\alpha-2 b+R B V$ alone). The breakdown of the SVR rates between the previous nonresponders and relapsers to previous SOC revealed significantly different outcomes. Previous SOC relapsers showed SVR rates of $69 \%$ and $75 \%$ in the response-guided and fixed duration BOC arms, respectively, compared to $29 \%$ in the control arm (retreatment with peg-IFN $\alpha-2 b+\mathrm{RBV}$ alone). The SVR rates in previous SOC partial responders were $40 \%$ and $52 \%$ in the response-guided and fixed-duration therapy BOC arms, respectively, compared to $7 \%$ following retreatment with peg-IFN $\alpha-2 b+$ RBV alone. Finally, the 4-week Peg-IFN $\alpha-2 b+$ RBV lead-in phase was helpful in predicting which patients (less than $1 \log _{10}$ HCV-RNA first-month decline) would have a lower chance of SVR. In addition, response during the first month of $\mathrm{BOC}$ was a predictor of SVR, as the rates in the BOC arms were higher in patients with undetectable HCV-RNA at week 8 of therapy (ie, week 4 of adding BOC). ${ }^{14,19}$

\section{$\mathrm{HCV}$ resistance to $\mathrm{BOC}$}

The selection of $\mathrm{HCV}$ variants that are resistant to active-site protease inhibitors by amino acid substitutions in the HCV 
protease domain of NS3 was demonstrated in vitro and in clinical trials of DAA monotherapy. ${ }^{22-28}$ Several amino acid positions are associated with resistance, yet others may act as compensatory mutations that restore fitness to resistant isolates. Table 1 summarizes the available data to date on the emergence of $\mathrm{HCV}$ resistance to BOC and other NS3/4A protease inhibitors.

The emergence of compound-specific HCV resistance is rapid in vivo, and can even occur within the first 2 weeks of exposure to a given DAA; ${ }^{17,29-31}$ however, some resistant strains may show reduced fitness. ${ }^{32} \mathrm{HCV}$ is a highly variable virus with a high mutation rate and a large population size that circulates as a swarm of closely related variants that can be rapidly selected. ${ }^{33}$ Minority-resistant HCV variants to new DAAs (not detectable by direct population sequencing) can be hidden within the complex genetic pool of the virions that circulate in a single infected patient. ${ }^{34}$ Using clonal sequence analysis, Susser et al found that minority resistance mutations can be selected at six positions within the HCV NS3 protease during BOC therapy, although 2 weeks after the end of treatment with $400 \mathrm{mg}$ BOC twice or three times daily, the frequency of resistant variants declines and the number of wild-type viruses increases to $95 \% .{ }^{35}$ However, it remains to be determined if such low-frequency resistant variants can compromise subsequent treatment options in the case of treatment failure, because the rapid selection of low-frequency resistant variants was observed during retreatment. ${ }^{29}$

The available data on $\mathrm{HCV}$ resistance have been reviewed recently. ${ }^{12,36}$ A major feature of resistance to $\mathrm{HCV}$ protease inhibitors is cross-resistance. The most relevant resistance mutations are substitutions in residues R155 and A156, which confer high levels of resistance to BOC and TPV and crossresistance to most NS3 protease inhibitors. Other mutations at V36, T54, and V170 are associated with low levels of resistance to both TPV and BOC. It is important to note that (i) some TPV-resistant variants remain detectable for up to 4 years after cessation of treatment, ${ }^{37}$ and (ii) that late relapse

Table I Mutations in the HCV NS3/4A protease inducing resistance to $\mathrm{HCV}$ protease inhibitors

\begin{tabular}{|c|c|}
\hline \multicolumn{2}{|l|}{ Linear } \\
\hline BOC & $\begin{array}{l}\text { V36A/M T54S/A V55A RI55K/T/Q AI56S } \\
\underline{\mathrm{A} I 56 \mathrm{~T} / \mathrm{V} V 170 \mathrm{~A} / \mathrm{T}}\end{array}$ \\
\hline TPV & V36A/M T54S/A RI55K/T/Q AI56S AI56T/V \\
\hline Narlaprevir & V36A/M T54S/A RI55K/T/Q AI56S Al56T/V \\
\hline \multicolumn{2}{|l|}{ Macrocyclic } \\
\hline Ist generation & Q80R/K R/55K/T/Q Al56T/V DI68A/E/G/H/T/Y \\
\hline 2nd generation & Al56S AI56T/V \\
\hline
\end{tabular}

Note: Cross-resistance mutations are underlined. ${ }^{12,36,42}$ may occur 24-36 weeks after TPV + peg-IFN- $\alpha+$ RBV therapy. ${ }^{31}$

HCV-resistant mutations can also emerge rapidly when BOC is used in monotherapy or is combined with pegIFN- $\alpha .{ }^{35}$ After BOC monotherapy, high frequencies of resistant variants were detected by clonal sequencing of $\mathrm{HCV}$ quasi-species in some patients at their 1-year follow-up. Moreover, resistant mutations are rapidly selected during retreatment with $\mathrm{BOC}+$ peg-IFN- $\alpha$ in some patients. ${ }^{29,38}$ In the SPRINT-1 trial emergence of resistant viruses, assessed by population sequencing, was detected early on viral breakthrough, mainly in mutations V36M, T54S, and R155K ( $>25 \%$ of samples), as well as T54A, V55A, R155T, A156S, V158I, and V170A (5\%-25\% of samples), and V36A, V36L, and I170T ( $<5 \%$ of samples). ${ }^{20}$ In addition, more than $25 \%$ of patients with viral breakthroughs carried cross-resistant mutations of both BOC and TPV. ${ }^{20}$ Data from the follow-up study, P05063 (NCT00689390), indicate that at least one resistant mutation persists for more than 1 year in patients who did not achieve SVR in previous BOC trials ( $\mathrm{n}=174) .{ }^{39}$ The most common resistance mutations were R155K (64\%), T54S (54\%), V36M (54\%), and T54A (22\%) during follow-up. Furthermore, the overall reversion to the wild-type virus was seen in $59 \%$ of the patients over a 2 -year period, but T54S- and R155K-carrying viruses reverted more slowly. The authors reported no late relapse in patients who achieved SVR $(n=290)$ in this follow-up cohort. ${ }^{39}$

Because HCV isolates are widely variable, and infections with $\mathrm{HCV}$ genotypes other than genotype 1 account for a large number of chronic carriers worldwide, ${ }^{40}$ defining the variability of $\mathrm{HCV} \mathrm{NS3/4A} \mathrm{protease} \mathrm{in} \mathrm{natural} \mathrm{isolates} \mathrm{will}$ be an important step in determining the potential selection of naturally resistant strains, as in the case of human immunodeficiency virus (HIV). ${ }^{41}$ A relevant polymorphism of NS3/4 proteases between HCV subtypes was found in sites associated either with resistance or with compensatory mutations after an analysis of more than 350 worldwide viral isolates (genotypes 1-6). ${ }^{42}$ For instance, V170A (which confers low levels of resistance to BOC) was present in 184/275 HCV genotype 1 isolates, and D168V/A was an amino acid signature in HCV genotype 3, which explains the reduced sensitivity of genotype 3 viruses to ciluprevir, and potentially to other protease inhibitors. ${ }^{42}$ The different genetic barriers to resistance between HCV subtypes $1 \mathrm{a}$ and $1 \mathrm{~b}$ illustrate the relevance of the variation between the genotypes and subtypes. The genetic barrier refers to the number of nucleotide substitutions required for the virus to acquire resistance to the drug. For BOC and TPV, the differences 
in genetic barriers include higher viral breakthrough rates and the selection of resistant variants observed in patients infected with subtype 1a, compared to those with subtype $1 \mathrm{~b}$. The resistance mutation, $\mathrm{R} 155 \mathrm{~K}$, emerges through a single nucleotide substitution in subtype 1a viruses, but requires two different substitutions in subtype $1 \mathrm{~b}$ viruses. ${ }^{43}$

Later studies involving a large number of patients also detected variants associated with resistance to PI in $5.5 \%$ and $1.4 \%$ of patients from the United States, Switzerland, and Germany who were infected with subtypes 1a or $1 \mathrm{~b}$, respectively, including the V36L/M and R115K variants associated with low or high-level resistance. ${ }^{44}$ In HCV genotype 1 -infected patients, $0.9 \%$ and $0.7 \%$ of viruses carried the $\mathrm{V} 36 \mathrm{M}$ or the $\mathrm{R} 155 \mathrm{~K}$ variants, respectively, and patients with the $\mathrm{R} 155 \mathrm{~K}$ virus appeared to have slower viral load declines during TVR + peg-IFN- $\alpha+$ RBV treatment than those with wt viruses. Finally, in patients from Australia, Switzerland, and the UK, the prevalence of single resistance mutations to NS3 protease inhibitors can account for up to $4.4 \%$ of viral isolates, and the frequencies for single or combined resistance mutations to NS3 protease and/or NS5b polymerase inhibitors can be found in up to $21.5 \%, 44.4 \%$, or $41.8 \%$ for subtypes $1 \mathrm{a}, 1 \mathrm{~b}$, or $3 \mathrm{a}$, respectively. ${ }^{45}$ Although the overall frequency of single resistance mutations is low in all of these studies, naturally occurring polymorphisms that confer resistance to DAAs could eventually compromise the treatment response of DAA-based regimes. ${ }^{46}$

In summary, the absence of response to triple $\mathrm{BOC}+$ pegIFN- $\alpha+R B V$ therapy is associated with the selection of viral resistant mutations. Because several second-generation NS3 protease inhibitors are in advanced clinical development, the selection of viral resistance may compromise future therapeutic options involving DAAs of the same class, and therefore, should be avoided whenever possible.

\section{Dosing, patient adherence, and AEs}

There are some concerns regarding patients' ability to follow the dosing scheme for these new regimes. BOC dosing consists of four $200 \mathrm{mg}$ capsules three times daily (8-hour intervals, with meals). Furthermore, the capsules cannot be dissolved nor broken. Regular treatment duration is 48 weeks. After the first 4-week lead-in phase with peg-IFN- $\alpha+\mathrm{RBV}$, patients are given the combination $\mathrm{BOC}+$ peg-IFN- $\alpha+\mathrm{RBV}$ during an additional 32-week period, followed by 12 weeks of peg-IFN- $\alpha+$ RBV alone to complete the 48 -week total treatment duration schedule. Treatment-naïve patients may be eligible for response-guided therapy (RGT) to reduce the total treatment duration to 28 weeks without detrimental effect on overall SVR rates. ${ }^{21}$ However, better SVR rates were observed with the 48 -week treatment in prior partialand non-responders. ${ }^{14}$

Adherence will be a key factor in assuring the success of new therapies, especially in currently approved regimes that use only one DAA, because of the evidenced risk of viral resistance to first-generation protease inhibitors when drug levels drop during treatment. ${ }^{47}$ This issue is particularly relevant because viral mutants can emerge with crossresistance profiles to newer second-generation linear and macrocyclic NS3 protease inhibitors.

Administering BOC three times daily, added to twicedaily RBV and once-weekly peg-IFN- $\alpha$, is a complicated dosing profile that may compromise triple therapy regimes. Second-generation protease inhibitors need to minimize these problems. In addition, triple BOC + peg-IFN- $\alpha+\mathrm{RBV}$ therapy can be associated with AEs that may be serious enough to compromise adherence and/or result in treatment discontinuation.

The most common AEs in subjects taking BOC (800 mg) plus peg-IFN- $\alpha+\mathrm{RBV}$ are fatigue, headache, anemia, nausea, and dysgeusia (26\%). ${ }^{17,18,20}$ The frequency of anemia is more common in patients receiving $\mathrm{BOC}+\mathrm{SOC}$ compared to those receiving SOC alone, ${ }^{18,20}$ and a similar picture is seen with TPV. ${ }^{31,48}$ In Phase III trials, anemia and dysgeusia were more common in the BOC arms than in the SOC control arms, ${ }^{19,21}$ and $40 \%$ of patients used epoietin alfa in the SPRINT-1 trial. ${ }^{18}$ Therefore, there is a risk of additive toxic effects. Both BOC and TPV cause anemia, but because no head-to-head comparison is currently available, it is not possible to know which regime causes more anemia. Recent communications have shown that for both BOC and TPV, a $\mathrm{RBV}$ reduction up to $600 \mathrm{mg}$ per day does not impair treatment response, and therefore, should be the first step in the management of anemia (European Association for the Study of the Liver Meeting 2012). If it is necessary to discontinue RBV, then BOC should also be stopped. Finally, BOC is metabolized by liver enzymes such as cytochrome P450 (CYP450), and several drug-drug interactions are currently under examination by ongoing studies that also require careful monitoring. ${ }^{49,50}$

\section{Conclusions}

The addition of BOC to peg-IFN- $\alpha+$ RBV significantly increases the possibility of recovery in HCV genotype 1-infected patients: from an overall $40 \%$ with pegIFN- $\alpha+$ RBV alone to up $75 \%$ with the concomitant use of BOC. ${ }^{14,15,51}$ BOC in combination with peg-IFN- $\alpha+\mathrm{RBV}$ is a 
more effective treatment for chronic HCV genotype 1 infection than peg-IFN- $\alpha+$ RBV alone, for both treatment-naive patients and previous relapsers or partial responders to pegIFN- $\alpha+$ RBV SOC. However, triple therapy needs closer, more detailed, and more frequent monitoring because it is more often associated with AEs, and therapy failure is associated with the selection of resistant viruses.

Patients are more likely to develop complications over a 5-10 year term (ie, liver fibrosis F3-F4) and will benefit most from the new triple therapies. Furthermore, patients with a good prognosis (ie, liver fibrosis F0-F2) might also receive only peg-IFN- $\alpha+\mathrm{RBV}$ in certain situations (ie, if they carry a favorable IL28B genotype and/or respond to interferon during the first 4 weeks of therapy). Such patients may also wait for newer, more effective DAAs to be approved (ie, if there are concerns regarding the tolerability of triple therapy). In the subset of patients with a high likelihood of achieving SVR with SOC alone (ie, favorable clinical characteristics, IL28 genotype, and early viral response during SOC), the addition of a protease inhibitor may have little additional benefit in terms of SVR, but will deliver the advantage of shortened treatment duration. ${ }^{21,52}$ Nevertheless, patients with a significant $>1 \log _{10}$ reduction in HCV-RNA levels at week 4 of Peg-IFN- $\alpha+$ RBV lead-in (sensitivity to peg-IFN- $\alpha+\mathrm{RBV}$ ), have a significantly higher chance for SVR with BOC triple therapy. ${ }^{53,54}$

In another subset of patients, lack of sensitivity to peg-IFN- $\alpha+$ RBV may compromise the effectiveness of BOC. ${ }^{14,15,51}$ After 4 weeks of peg-IFN- $\alpha+$ RBV lead-in, patients with $<1 \log _{10}$ decline in HCV RNA showed significantly reduced SVR rates, increased levels of virological failure, and resistance mutations. ${ }^{15}$ The addition of BOC should be evaluated carefully in these patients, due to the risk for viral resistance in the case of treatment failure, although SVR rates with BOC triple therapy are higher in this subgroup than those obtained with peg-IFN- $\alpha+$ RBV alone. ${ }^{15}$ Alternatively, these patients have the option of waiting for new, more effective, second-generation dual DAAregimes. ${ }^{52,55}$ Exposure to $\mathrm{BOC}$ in previous null responders to peg-IFN- $\alpha+\mathrm{RBV}$ with $<1 \log _{10}$ decline in HCV RNA after the lead-in phase should be avoided since without the peg-IFN- $\alpha+$ RBV selective pressure BOC-resistant variants are rapidly selected. Reported results with TPV in previous null-responders are limited to SVR rates of $15 \%$ in patients with $<1 \log _{10}$ decline during the 4 -week lead-in period. ${ }^{54}$

Provisional guidelines and proposals for consensus are currently underway for the use of BOC and TPV. ${ }^{52,56,57}$ Ideally, a risk-benefit analysis should be performed for each patient to determine whether new triple therapies will be administered and to minimize the number of treated patients with low probability for achieving SVR (and selection for resistant viruses). Potential factors compromising the effectiveness of triple therapy include previous null-response to pegIFN- $\alpha+$ RBV SOC, adherence, AEs, side effects, advanced fibrosis, and availability of frequent HCV-RNA monitoring during treatment. New DAA-based regimes must follow strict treatment discontinuation rules (futility rules) based on viral load measurements to avoid functional monotherapy and the emergence of viral resistance in the absence of response. ${ }^{9,10}$ For BOC, all drugs (BOC, peg-IFN- $\alpha$, and RBV) must be stopped if HCV-RNA values are higher than or equal to $100 \mathrm{IU} / \mathrm{mL}$ at week 8 of triple therapy, or if HCV-RNA is found positive by a sensitive PCR assay at week 20 of triple therapy. In addition, if peg-IFN- $\alpha+\mathrm{RBV}$ administration is discontinued, BOC administration should be stopped immediately to avoid monotherapy. ${ }^{9,10}$

Finally, evaluation of the efficacy of BOC and other DAAs in special settings such as in decompensated cirrhosis, liver transplantation, and patients co-infected with HIV is urgently needed, because such patients are most in need of highly effective treatment regimes.

\section{Acknowledgments}

This work was supported by the Fondo de Investigación Sanitaria, Instituto de Salud Carlos III, Spanish Ministry of Science (PS09/01707, PI10/00512 and CIBER-esp/CIBERehd), and by Generalitat Valenciana (AP-053/10). FXL holds a PI position supported by the Fondo de Investigación Sanitaria, Instituto de Salud Carlos III, Spanish Ministry of Science.

\section{Disclosure}

The authors report no conflicts of interest in this work.

\section{References}

1. Heathcote EJ. Antiviral therapy: chronic hepatitis C. J Viral Hepat. 2007;14 Suppl 1:S82-S88.

2. Kronenberger B, Zeuzem S. New developments in HCV therapy. JViral Hepat. 2012;19 Suppl 1:S48-S51.

3. Cuevas JM, González-Candelas F, Moya A, Sanjuan R. Effect of ribavirin on the mutation rate and spectrum of hepatitis $\mathrm{C}$ virus in vivo. $J$ Virol. 2009;83(11):5760-5764.

4. Tam RC, Pai B, Bard J, et al. Ribavirin polarizes human T cell responses towards a Type 1 cytokine profile. J Hepatol. 1999;30(3):376-382.

5. Maylin S, Martinot-Peignoux M, Moucari R, et al. Eradication of hepatitis $\mathrm{C}$ virus in patients successfully treated for chronic hepatitis $\mathrm{C}$. Gastroenterology. 2008;135(3):821-829.

6. Cardoso AC, Moucari R, Figueiredo-Mendes C, et al. Impact of peginterferon and ribavirin therapy on hepatocellular carcinoma: incidence and survival in hepatitis $\mathrm{C}$ patients with advanced fibrosis. J Hepatol. 2010;52(5):652-657. 
7. Asselah T, Estrabaud E, Bieche I, et al. Hepatitis C: viral and host factors associated with non-response to pegylated interferon plus ribavirin. Liver Int. 2010;30(9):1259-1269.

8. Ge D, Fellay J, Thompson AJ, et al. Genetic variation in IL28B predicts hepatitis C treatment-induced viral clearance. Nature. 2009;461(7262): 399-401.

9. Boceprevir, EMA Label. http://www.ema.europa.eu/docs/en_GB/ document_library/EPAR_-_Public_assessment_report/human/002332/ WC500109789.pdf. Accessed May 15, 2012.

10. Boceprevir, FDA Label. http://www.accessdata.fda.gov/drugsatfda docs/label/2011/2022581bl.pdf. Accessed May 15, 2012.

11. Li XD, Sun L, Seth RB, Pineda G, Chen ZJ. Hepatitis C virus protease NS3/4A cleaves mitochondrial antiviral signaling protein off the mitochondria to evade innate immunity. Proc Natl Acad Sci U S A 2005;102(49):17717-17722.

12. Gelman MA, Glenn JS. Mixing the right hepatitis C inhibitor cocktail. Trends Mol Med. 2011;17(1):34-46.

13. Malcolm BA, Liu R, Lahser F, et al. SCH 503034, a mechanismbased inhibitor of hepatitis C virus NS3 protease, suppresses polyprotein maturation and enhances the antiviral activity of alpha interferon in replicon cells. Antimicrob Agents Chemother. 2006;50(3): 1013-1020.

14. Bacon BR, Gordon SC, Lawitz E, et al. Boceprevir for previously treated chronic HCV genotype 1 infection. NEngl J Med. 2011;364(13): 1207-1217.

15. Poordad F, McCone J, Bacon BR, et al. Boceprevir for untreated chronic HCV genotype 1 infection. N England J Med. 2011;364(13): 1195-1206.

16. Mangia A, Mottola L. Treatment of non-genotype 1 hepatitis $C$ virus patients. Curr Gastroenterol Rep. 2012;14(1):87-93.

17. Schiff E, Poordad E, Jacobson I, et al. Boceprevir (B) combination therapy in null responders (NR): response dependent on interferon responsiveness. J Hepatol. 2008;48 Suppl 2:S46.

18. Kwo P, Lawitz E, McCone J, et al. HCV SPRINT-1 final results: SVR from a phase 2 study of boceprevir plus pegintron (Peg-IFN alpha-2b)/ $\mathrm{RBV}$ in treatment-naive subjects with genotype 1 chronic hepatitis C. J Hepatol. 2009;50 Suppl 1:S4.

19. Bacon BR, Gordon SC, Lawitz E, et al. RESPOND-2 final results: high sustained virologic response among genotype 1 previous nonresponders and relapsers to peginterferon/ribavirin when re-treated with boceprevir plus PEGINTRON (Peginterferon alfa-2b)/ribavirin. Hepatology. 2010;52 Suppl 1:S430A.

20. Kwo PY, Lawitz EJ, McCone J, et al. Efficacy of boceprevir, an NS3 protease inhibitor, in combination with peginterferon alfa- $2 b$ and ribavirin in treatment-naive patients with genotype 1 hepatitis $\mathrm{C}$ infection (SPRINT-1): an open-label, randomised, multicentre phase 2 trial. Lancet. 2010;376(9742):705-716.

21. Bronowicki J, McCone J, Bacon BR, et al. Response-guided therapy (RGT) with boceprevir (BOC) + peginterferon alfa-2b/ribavirin (P/R) for treatment-naïve patients with hepatitis $\mathrm{C}$ virus (HCV) genotype $(\mathrm{G}) 1$ was Similar to a $48-W k$ fixed-duration regimen with $\mathrm{BOC}+\mathrm{P} / \mathrm{R}$ in SPRINT-2. Hepatology. 2010;52 Suppl 1:S881A.

22. Lu L, Pilot-Matias TJ, Stewart KD, et al. Mutations conferring resistance to a potent hepatitis $\mathrm{C}$ virus serine protease inhibitor in vitro. Antimicrob Agents Chemother. 2004;48(6):2260-2266.

23. Trozzi C, Bartholomew L, Ceccacci A, et al. In vitro selection and characterization of hepatitis $\mathrm{C}$ virus serine protease variants resistant to an active-site peptide inhibitor. J Virol. 2003;77(6): 3669-3679.

24. Lin C, Lin K, Luong YP, et al. In vitro resistance studies of hepatitis C virus serine protease inhibitors, VX-950 and BILN 2061: structural analysis indicates different resistance mechanisms. J Biol Chem. 2004; 279(17):17508-17514.

25. Mo H, Lu L, Pilot-Matias T, et al. Mutations conferring resistance to a hepatitis $\mathrm{C}$ virus (HCV) RNA-dependent RNA polymerase inhibitor alone or in combination with an HCV serine protease inhibitor in vitro. Antimicrob Agents Chemother. 2005;49(10):4305-4314.
26. Yi M, Tong X, Skelton A, et al. Mutations conferring resistance to SCH6, a novel hepatitis C virus NS3/4A protease inhibitor: Reduced RNA replication fitness and partial rescue by second-site mutations. J Biol Chem. 2005;281(12):8205-8215.

27. Seiwert S, Hong J, Lim S, Tan H, Kossen K, Blatt L [abstract]. Rev Antiviral Ther. 2007;1:56.

28. Zhou Y, Muh U, Hanzelka BL, et al. Phenotypic and structural analyses of hepatitis C virus NS3 protease arg155 variants: sensitivity to telaprevir (VX-950) and interferon alpha. J Biol Chem. 2007;282(31): 22619-22628.

29. Susser S, Forestier N, Welker MW, et al. Detection of resistant variants in the hepatitis $\mathrm{C}$ virus ns3 protease gene by clonal sequencing at long-term follow-up in patients treated with boceprevir. J Hepatol. 2009;50 Suppl 1:S12.

30. McHutchison JG, Everson GT, Gordon SC, et al. Telaprevir with peginterferon and ribavirin for chronic $\mathrm{HCV}$ genotype 1 infection. N Engl J Med. 2009;360(18):1827-1838.

31. Hezode C, Forestier N, Dusheiko G, et al. Telaprevir and peginterferon with or without ribavirin for chronic HCV infection. $N$ Engl J Med. 2009;360(18):1839-1850.

32. Sarrazin C, Kieffer TL, Bartels D, et al. Dynamic hepatitis C virus genotypic and phenotypic changes in patients treated with the protease inhibitor telaprevir. Gastroenterology. 2007;132(5):1767-1777.

33. Domingo E. Genetic variation and quasi-species. Curr Opin Genet Dev. 1992;2(1):61-63.

34. Nájera I, Holguín A, Quinones-Mateu ME, et al. Pol gene quasispecies of human immunodeficiency virus: mutations associated with drug resistance in virus from patients undergoing no drug therapy. $J$ Virol. 1995;69(1):23-31

35. Susser S, Welsch C, Wang Y, et al. Characterization of resistance to the protease inhibitor boceprevir in hepatitis $\mathrm{C}$ virus-infected patients. Hepatology. 2009;50(6):1709-1718.

36. Halfon $\mathrm{P}$, Locarnini $\mathrm{S}$. Hepatitis $\mathrm{C}$ virus resistance to protease inhibitors. J Hepatol. 2011;55(1):192-206.

37. Susser S, Forestier N, Vermehren J, et al. Decline of detectable resistance mutations within the NS3 protease quasispecies during long-term follow-up after treatment with telaprevir. $J$ Hepatol. 2010;52 Suppl 1:S300.

38. Vermehren J, Susser S, Lange CM, et al. Mutations selected in the hepatitis $\mathrm{C}$ virus NS3 protease domain during sequential treatment with boceprevir with and without pegylated interferon alfa-2b. J Viral Hepat. 2012;19(2):120-127.

39. Vierling JM, Ralston R, Lawitz EJ, et al. Long-term outcomes following combination treatment with boceprevir plus pegintron/ribavirin $(\mathrm{P} / \mathrm{R})$ in patients with chronic hepatitis $\mathrm{C}$, genotype 1 (CHC-G1). J Hepatol. 2010;52 Suppl 1:S470-S471.

40. Simmonds P. Genetic diversity and evolution of hepatitis C virus 15 years on. J Gen Virol. 2004;85(11):3173-3188.

41. Condra JH, Schleif WA, Blahy OM, et al. In vivo emergence of HIV-1 variants resistant to multiple protease inhibitors. Nature. 1995;374(6522):569-571.

42. López-Labrador FX, Moya A, González-Candelas F. Mapping natural polymorphisms of hepatitis $\mathrm{C}$ virus NS3/4A protease and antiviral resistance to inhibitors in worldwide isolates. Antivir Ther. 2008;13(4):481-494.

43. Sarrazin C, Zeuzem S. Resistance to direct antiviral agents in patients with hepatitis C virus infection. Gastroenterology. 2010;138(2):447-462.

44. Kuntzen T, Timm J, Berical A, et al. Naturally occurring dominant resistance mutations to hepatitis $\mathrm{C}$ virus protease and polymerase inhibitors in treatment-naive patients. Hepatology. 2008;48(6): 1769-1778

45. Gaudieri S, Rauch A, Pfafferott K, et al. Hepatitis C virus drug resistance and immune-driven adaptations: Relevance to new antiviral therapy. Hepatology. 2009;49(4):1069-1082.

46. Kieffer TL, Sarrazin C, Miller JS, et al. Telaprevir and pegylated interferon-alpha-2a inhibit wild-type and resistant genotype 1 hepatitis C virus replication in patients. Hepatology. 2007;46(3): 631-639. 
47. Rong L, Dahari H, Ribeiro RM, Perelson AS. Rapid emergence of protease inhibitor resistance in hepatitis C virus. Sci Transl Med. 2010;2(30):30-32.

48. McHutchison JG, Manns MP, Muir AJ, et al. Telaprevir for previously treated chronic HCV infection. $N$ Engl J Med. 2010;362(14): 1292-1303.

49. Klibanov OM, Vickery SB, Olin JL, Smith LS, Williams SH. Boceprevir: a novel NS3/4 protease inhibitor for the treatment of hepatitis C. Pharmacotherapy. 2012;32(2):173-190.

50. Hezode C. Boceprevir and telaprevir for the treatment of chronic hepatitis C: safety management in clinical practice. Liver Int. 2012; 32 Suppl 1:S32-S38.

51. Bacon BR, Khalid O. Triple therapy with boceprevir for HCV genotype 1 infection: Phase III results in relapsers and nonresponders. Liver Int. 2012;32 Suppl 1:S51-S53.

52. Ramachandran P, Fraser A, Agarwal K, et al. UK consensus guidelines for the use of the protease inhibitors boceprevir and telaprevir in genotype 1 chronic hepatitis $\mathrm{C}$ infected patients. Aliment Pharmacol and Ther. 2012;35(6):647-662.

53. Reddy KR, Bruno S, Rossaro L, et al. Predictors of sustained virologic response among treatment-naive patients with hepatitis $\mathrm{C}$ virus genotype 1 when treated with boceprevir (BOC) plus peginterferon alfa-2b/ ribavirin (Pr). J Hepatol. 2011;54 Suppl 1:S190-S190.
54. Foster GR, Zeuzem S, Andreone P, et al. Subanalyses of the telaprevir lead-in arm in the realize study: response at week 4 is not a substitute for prior null response categorization. J Hepatol. 2011;54 Suppl 1: S3-S4.

55. Lok AS, Gardiner DF, Lawitz E, et al. Preliminary study of two antiviral agents for hepatitis C genotype 1. N Engl J Med. 2012;366(3): 216-224.

56. Jacobson IM, Pawlotsky J-M, Afdhal NH, et al. A practical guide for the use of boceprevir and telaprevir for the treatment of hepatitis $\mathrm{C}$. J Viral Hepat. 2012;19 Supp1 2:S1-S26.

57. Thomas DL, Bartlett JG, Peters MG, Sherman KE, Sulkowski MS, Pham PA. Provisional guidance on the use of hepatitis $\mathrm{C}$ virus protease inhibitors for treatment of hepatitis C in HIV-infected persons. Clin Infect Dis. 2012;54(7):979-983.

58. Nair LG, Sannigrahi M, Bogen S, et al. P4 capped amides and lactams as HCV NS3 protease inhibitors with improved potency and DMPK profile. Bioorg Med Chem Lett. 2010;20:567-570.

59. Berenguer M, López-Labrador FX. Boceprevir in the treatment of chronic hepatitis $\mathrm{C}$ virus infection. Virus Adaptation and Treatment. 2011;3:7-17.
Biologics: Targets \& Therapy

\section{Publish your work in this journal}

Biologics: Targets \& Therapy is an international, peer-reviewed journal focusing on the patho-physiological rationale for and clinical application of Biologic agents in the management of autoimmune diseases, cancers or other pathologies where a molecular target can be identified. This journal is indexed on PubMed Central, CAS, EMBase, Scopus

\section{Dovepress}

and the Elsevier Bibliographic databases. The manuscript management system is completely online and includes a very quick and fair peerreview system, which is all easy to use. Visit http://www.dovepress com/testimonials.php to read real quotes from published authors. 